\title{
Measurement of Handgrip Strength of North Indian Male Farmers and Its Implications in Design of Farm Equipment
}

\author{
Sandeep Singh Kharb ${ }^{1 *}$, Rajendra Madhukar Belokar ${ }^{2}$, Suman Kant ${ }^{2}$, Milap Sharma ${ }^{2}$ \\ ${ }^{1}$ Poornima Institute of Engineering and Technology, Jaipur 302022, India \\ ${ }^{2}$ Production and Industrial Engineering Department, Punjab Engineering College (Deemed to be University), Chandigarh \\ 160012, India
}

Corresponding Author Email: sandeep.kharb@poornima.org

https://doi.org/10.18280/i2m.190509

Received: 10 May 2020

Accepted: 23 July 2020

\section{Keywords:}

isometric handgrip strength, musculoskeletal

disorders, anthropometry, manual tools

\begin{abstract}
As a systematic ergonomics improvement process has always been prevailing in mankind to maximize the human performance within its body's capabilities and limitations, by providing it a safe workplace and equipment. In addition to this custom, a scrutinized effort is made to associate worker's strength with the force/torque required to operate the tool/equipment in agrarian society of Haryana state (i.e. northern part of India). Therefore, an isometric hand grip strength for both hands (dominant and other one) base data of 200 male agricultural workers (age 18-60 years) from five districts has been measured with baseline handgrip dynamometer. However 20-50 years age group are found actively involved in arduous agricultural activities. On summarizing the Statistical information for the age group 20-50 years (173 subjects) such as mean, standard deviation (SD), skewness, kurtosis, $5^{\text {th }}$ and $95^{\text {th }}$ percentiles it has been observed that Dominant handgrip strength $(46.14 \pm 7.13 \mathrm{~kg})$ is significantly different $(\mathrm{p}<0.05)$ from the opposite handgrip strength $(44.50 \pm 7.48 \mathrm{~kg})$. Further study also reveals that the strength of handgrip declines significantly $(\mathrm{p}<0.05)$ with the increasing age.
\end{abstract}

\section{INTRODUCTION}

Three pillars of Indian economy are- Industrial sector, service sector and agriculture \& allied sector. The service sector contributed the most 57.9\% in Indian GDP 2016-2017, Industry (24.2\%) and agriculture sector contributed $17.9 \%$. But in terms of workforce indulgence, agriculture sector engages the highest manpower $(67 \%)$ in India [1]. Although agricultural sector is generally recognized as the country's most hazardous sector. Various researchers has been disclosed the high rates of musculoskeletal disorders (MSDs) in the different agricultural activities, which are evidence of ergonomic risk and be pointed out. Till today, there is limited history of implementation of ergonomic approaches in modification of agricultural tools and equipment design. Therefore, it is essential to give attention towards ergonomically fit design of farm tools, So as to enhance comfort, safety and performance of the workers for the higher productivity [2]. The performance of workers depends upon three factors: type of activity, design of tools and the body characteristics of workers such as body dimensions and strength etc. To perform the task efficiently, the body characteristics (muscle strength) of the workers must match with energy demands in operating the tool. Because, it is necessary to exert required force and torques by muscles to operate and control the various manual tools to sustain or to lift the load without inflicting any personal injury. Hence, it is very essential to predict the relationship between the force requirement to operate the hand tools and specific muscle strengths of the worker.

Human muscular strength is mainly classified as static and dynamic strength. Isometric strength is the capacity of muscles to apply the force or torques in a lone maximal voluntary static exertion in which concerned joints remain fixed [3]. Isometric static strength measurement is simple and cheaper than dynamic strength measurement. Researchers has measured various static strength parameters (leg strength, grip strength, push/pull strength) from the different regions of India $[4,5]$. Now a days, ergonomists rely over the anthropometric characteristics and muscular strength of workers to develop the better and satisfactory product output [6]. Therefore, it is required to develop the isometric strength database of the workers to know the capabilities and limitations for their optimized performance. Author defined the isometric static strength as the maximal voluntary static force, which can be generated during isometric contraction at the optimum joint angles [7]. Gender, age, posture (forearm and wrist position), grip span, palm length, type of activity and measuring technique has been reported as the most effective parameters, which affect the handgrip strength for the maximal voluntary contraction (MVC) [8-10]. Author suggested the optimum grip span range as $50-65 \mathrm{~mm}$ and $45-60 \mathrm{~mm}$ for males and females respectively [11]. Isometric handgrip strength is observed higher for younger workers and declines gradually as they get older [12-15]. Author analysed the relation among handgrip strength, stature \& weight of the workers and observed the positive proportionality [16].

Ergonomists suggests that any device, tool or equipment must be designed for the weakest one in its specific operating class. Hence, these must be developed according to the $5^{\text {th }}$ percentile of the weakest age group as grip strength declines significantly with the increasing age of the workers. Though, 
various comparative studies among workers of different regions have shown the significant difference in the body characteristics (human capabilities, strength and limitations). Hence, understanding of body characteristics of regionspecific population is very important for the safe and better design agricultural tools and equipment. Literature shows no availability of isometric handgrip strength data for Haryanvi farmers, which motivated the authors to conduct the present survey for data collection of handgrip strength of 200 male farmers. The collected strength data is classified in three age groups ( $<30 \mathrm{yr}, 30-40 \mathrm{yr}$ and $>40 \mathrm{yr}$ ) and further analysed to know the variation in strength with respect to age. Optimized equipment design on the basis of weakest class will help in improvement of performance as well as safety of each worker.

\section{METHODS}

\subsection{Subjects assortment}

Data is collected from five districts (Panipat, Sonepat, Jind, Rohtak, Bhiwani) of Haryana, one of the Northern state in India. State is segregated in three zones on the basis of agroeco regions, districts (for the present study) are selected to cover all the three zones. Village heads (Sarpanch) were taken in confidence before starting the selection of subjects and data collection. Volunteer participants were chosen randomly and selected as subject after ascertainment of their normal health. Forty males were selected from each district, therefore in total 200 subjects between the age of 18 and 60 years were considered for the present study. All the farmers were selected from the self-farming class. Additionally, all the subjects were paid apt remuneration for their loss of work during the experiments.

\subsection{Instrument}

Table 1 shows information about the different tools used in the various anthropometric measurement.
Table 1. Equipment summary used in measurement

\begin{tabular}{ccccc}
\hline $\begin{array}{c}\text { Sr. } \\
\text { no. }\end{array}$ & $\begin{array}{c}\text { Name of the } \\
\text { instrument }\end{array}$ & $\begin{array}{c}\text { Range of the } \\
\text { instrument }\end{array}$ & $\begin{array}{c}\text { Least } \\
\text { count }\end{array}$ & $\begin{array}{c}\text { Body } \\
\text { dimension }\end{array}$ \\
\hline $\mathbf{1}$ & $\begin{array}{c}\text { Portable } \\
\text { anthropometric } \\
\text { kit }\end{array}$ & $0-200 \mathrm{~cm}$ & $1 \mathrm{~mm}$ & Stature \\
$\mathbf{2}$ & $\begin{array}{c}\text { Digital } \\
\text { Weighing scale }\end{array}$ & $0-150 \mathrm{~kg}$ & $100 \mathrm{gm}$ & $\begin{array}{c}\text { Body } \\
\text { weight } \\
\text { Grip } \\
\text { strength }\end{array}$ \\
$\mathbf{3}$ & $\begin{array}{c}\text { Baseline } \\
\text { Dynamometer }\end{array}$ & $0-90 \mathrm{~kg}$ & $100 \mathrm{gm}$ & \\
\hline
\end{tabular}

\subsection{Procedure}

For the survey, a team of well trained three scholars was sent to a predetermined locality. Firstly, village head (sarpanch) was approached and convinced about the aim of research. Volunteered participants were chosen randomly and observed to make sure that they were not having any musculoskeletal disorder and physical abnormality. All the observed participants were selected as subject for measurements after giving their consent. Before data collection all the subjects were made familiar with procedure of measurement, then the measurement was started. Each participant was asked to stand straight with stretched shoulder and hanging arms. Then, the handgrip strength for both hands (dominant and opposite) was measured in neutral trunk and wrist position (Figure 1). For the accurate measurements, a rest pause of 3-5 min was given to each subject between the consecutive test in order to avoid muscles fatigue. During the data recording, subject was needed to reach his maximum strength limit within $2 \mathrm{~s}$ and then to maintain that peak strength for subsequent $3 \mathrm{~s}[4,17]$. Grip span of the dynamometer was maintained at $55 \mathrm{~mm}$ during the experimentation because the researchers has suggested the most favourable grip span range for males as 50$60 \mathrm{~mm}$ to obtain the maximal voluntary contraction. The strength data was noted in kilograms. For each hand 2 replications were recorded and the average of those two readings were considered as the grip strength of the same hand.

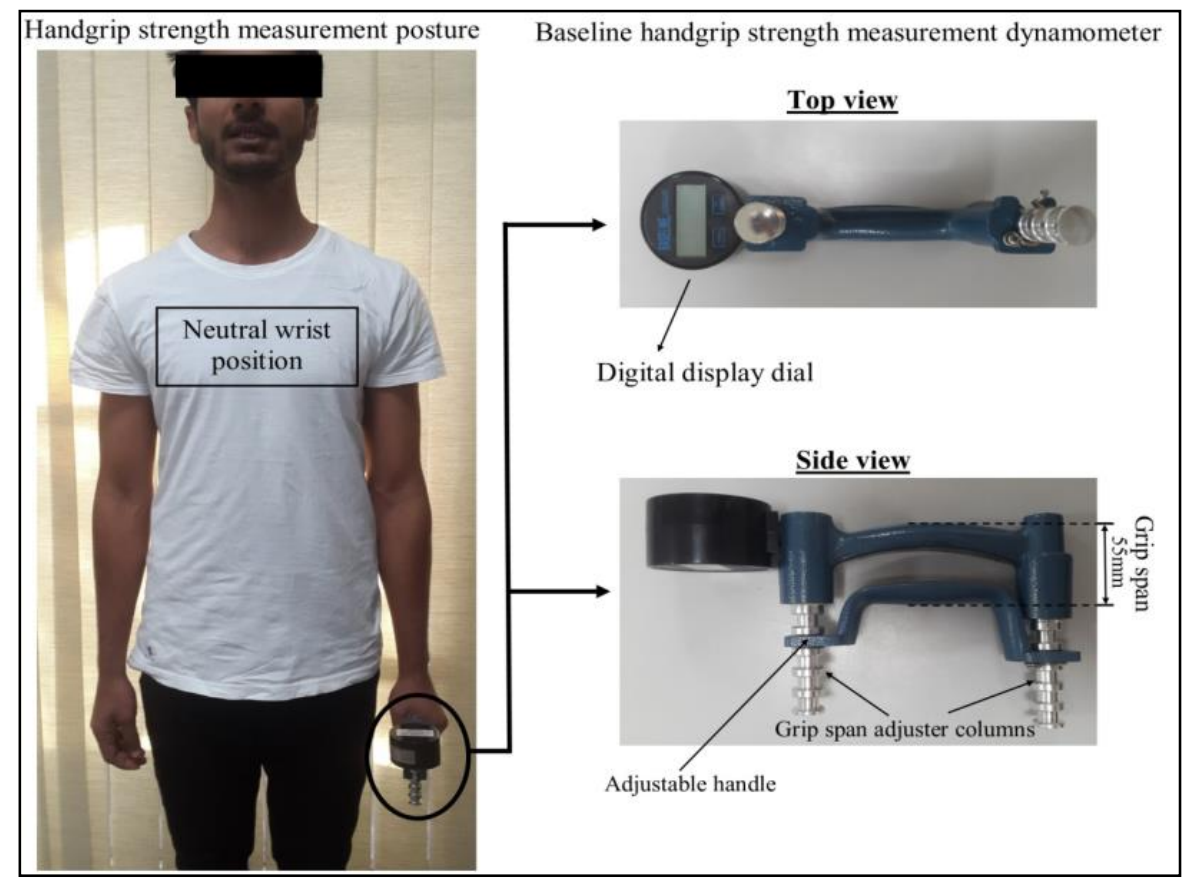

Figure 1. Handgrip strength measurement technique and the dynamometer description 
Table 2. Descriptive statistics of anthropometric traits of the subjects $(n=200)$

\begin{tabular}{cccccc}
\hline Sr. No. & & Stature $(\mathbf{c m})$ & Weight $(\mathbf{k g})$ & Dominant handgrip strength (kg) & Opposite handgrip strength (kg) \\
\hline $\mathbf{1}$ & Minimum & 156.40 & 47.5 & 29.40 & 26.70 \\
$\mathbf{2}$ & Maximum & 188.20 & 99.60 & 62.90 & 63.30 \\
$\mathbf{3}$ & Mean & 171.92 & 68.43 & 46.14 & 44.50 \\
$\mathbf{4}$ & SEM & 0.47 & 0.80 & 0.54 & 0.57 \\
$\mathbf{5}$ & SD & 6.13 & 10.56 & 7.13 & 7.48 \\
$\mathbf{6}$ & CV & 3.56 & 15.43 & 15.45 & 16.81 \\
$\mathbf{7}$ & Skewness & -0.113 & 0.489 & -0.072 & 0.02 \\
$\mathbf{8}$ & Kurtosis & -0.188 & -0.157 & -0.117 & -0.173 \\
$\mathbf{9}$ & 5th percentile & 160.56 & 53.02 & 33.42 & 31.32 \\
$\mathbf{1 0}$ & 95th percentile & 182.12 & 87.86 & 58.96 & 57.68 \\
$\mathbf{1 1}$ & Variance & 37.65 & 111.61 & 50.80 & 56 \\
\hline
\end{tabular}

$\mathrm{SEM}=$ standard error of mean; $\mathrm{SD}=$ standard deviation; $\mathrm{CV}=$ coefficient of variation; $\mathrm{n}=$ sample size

Table 3. The mean (SD) values of the parameters for various age groups (for 20-50 years)

\begin{tabular}{cccccc}
\hline $\begin{array}{c}\text { Sr. } \\
\text { No. }\end{array}$ & $\begin{array}{c}\text { Anthropometric } \\
\text { measurement }\end{array}$ & $\begin{array}{c}\mathbf{2 0 - 2 9} \text { yr } \\
\text { Mean (SD) Group I }\end{array}$ & $\begin{array}{c}\mathbf{3 0 - 3 9} \text { yr } \\
\text { Mean (SD) Group II }\end{array}$ & $\begin{array}{c}\text { 40-50 yr } \\
\text { Mean (SD) Group III }\end{array}$ & $\begin{array}{c}\text { Whole Sample } \\
\text { Mean (SD) }\end{array}$ \\
\hline $\mathbf{1}$ & Sample, $\mathrm{n}$ & 82 & 62 & 29 & 173 \\
$\mathbf{2}$ & Age, year & $24.69(2.81)$ & $34.14(3.30)$ & $45(3.26)$ & $31.48(8.04)$ \\
$\mathbf{3}$ & Stature, cm & $172.60(5.6)$ & $172.14(6.58)$ & $169.51(6.21)$ & $171.92(6.13)$ \\
$\mathbf{4}$ & Weight, kg & $66.48(9.54)$ & $71.87(10.82)$ & $66.62(11.25)$ & $68.43(10.56)$ \\
$\mathbf{5}$ & BMI & $22.31(3.0)$ & $24.24(3.30)$ & $23.18(3.63)$ & $23.15(3.32)$ \\
$\mathbf{6}$ & Dominant handgrip strength, kg & $47.52(6.69)$ & $46.84(7.12)$ & $40.75(5.92)$ & $46.14(7.13)$ \\
$\mathbf{7}$ & Opposite handgrip strength, kg & $45.31(7.08)$ & $45.38(7.33)$ & $40.29(7.73)$ & $44.50(7.48)$ \\
\hline
\end{tabular}

\subsection{Statistical analysis}

All the raw data was analysed statistically using Microsoft Excel software, IBM SPSS statistics version-23 for windows. Shapiro-Wilk test $(\mathrm{p}>0.05)$, visual assessment (Q-Q plot), skewness and kurtosis were used to examine the normality of data. None of the data was found violating the assumptions of normality. Before selection of student independent t-test, Levene's test was performed to verify its assumption (homogeneity of variances). Independent t-test was performed to find the statistical significant variation in the mean of different parameters body mass index (BMI), dominant hand strength and opposite hand strength $(\mathrm{p}<0.05)$.

\section{RESULTS}

Four anthropometric parameters (stature, weight, handgrip strength for dominant and opposite hand) are measured for 200 subjects in the age of 18-60 years from the five districts of Haryana covering its all three zones. However 20-50 years age group are found actively involved in arduous agricultural activities. Hence, Descriptive statistics of 20-50 years age group such as minimum, maximum, mean, SEM, SD, CV, skewness, kurtosis, $5^{\text {th }}$ and $95^{\text {th }}$ percentile values for 4 parameters (strength, weight, dominant and opposite handgrip strength) is presented in Table 2. Mean of the measurement of stature, weight, dominant and opposite handgrip strengths are $171.92 \pm 6.13 \mathrm{~mm}, 68.43 \pm 10.56 \mathrm{~kg}, 46.14 \pm 7.13 \mathrm{~kg}$ and $44.50 \pm 7.48 \mathrm{~kg}$ respectively. Handgrip strength of dominant hand is found to be higher and significantly differ than that of opposite hand. The mean of dominant and opposite handgrip strength are compared and indicate that the dominant handgrip strength is higher than that of opposite hand by $3.6 \%$. The results of t-test indicate that dominant and opposite handgrip strength are significantly different $(\mathrm{p}<0.05)$. This may be due to the development of muscles of the dominant hand more than that of opposite hand muscles. Because the handgrip strength depends upon the list of factors i.e. gender, physical fitness, age, muscle development of the preferred hand etc.

\subsection{Comparison of the handgrip strength of various age groups}

The main sample of 200 subjects is classified in three groups on the basis of age viz., 20-29 years, 30-39 years and $40-50$ years. The percentage of subjects in each group are $49 \%$, $31.5 \%$ and $19.5 \%$ respectively. The mean and SD values for all three groups (viz., 20-29 years, 30-39 years and 40-50 years) surveyed for north Indian male farmers pertaining to 4 parameters are calculated and shown in Table 3 .

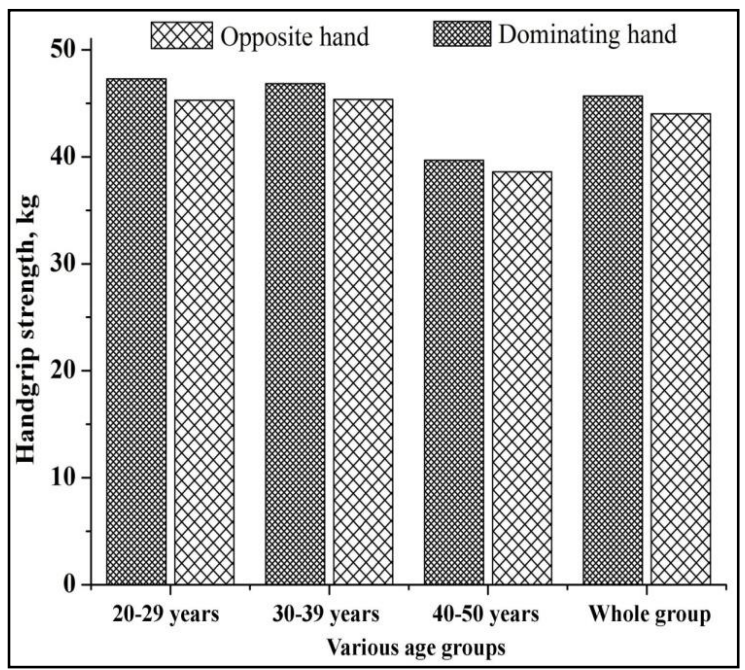

Figure 2. Handgrip strength for dominant and opposite hand for male agricultural workers of various age groups 
Table 4. Comparison of mean (SD) isometric handgrip strength data of male agricultural workers of Haryana state with data of other states of India

\begin{tabular}{|c|c|c|c|c|c|c|}
\hline Sr. No. & State & $\begin{array}{l}\text { Sample } \\
\text { Size }\end{array}$ & $\begin{array}{c}\text { Dominant handgrip } \\
\text { strength (N) } \\
\text { Mean (SD) } \\
\end{array}$ & $\begin{array}{c}\text { Opposite handgrip strength }(\mathbf{N}) \\
\text { Mean (SD) }\end{array}$ & $\begin{array}{c}\text { t-value for } \\
\text { dominant } \\
\text { hand }\end{array}$ & $\begin{array}{l}\text { t-value for } \\
\text { opposite } \\
\text { hand }\end{array}$ \\
\hline 1 & Present study & 200 & $452.63(69.94)$ & $436.54(73.38)$ & ----- & ----- \\
\hline 2 & MP & 825 & $404(110)$ & $377(110)$ & $7.03^{*}$ & $8.39^{*}$ \\
\hline 3 & $\mathrm{~J} \& \mathrm{~K}$ & 485 & $313(52)$ & $294(51)$ & $24.52^{*}$ & $23.82^{*}$ \\
\hline 4 & OR & 171 & $336(82)$ & $326(79)$ & $14.00^{*}$ & $13.17^{*}$ \\
\hline 5 & MH & 1249 & $326(66)$ & $313(65)$ & $22.97^{*}$ & $21.17^{*}$ \\
\hline 6 & $\mathrm{TN}$ & 618 & $412(87)$ & $388(106)$ & $5.94^{*}$ & $6.45^{*}$ \\
\hline
\end{tabular}

Note: measurement unit $=$ newton $(\mathrm{N}) ;^{*}=$ statistically significant $(\mathrm{p}<0.05)[18]$

Handgrip strength of group I is taken as reference (100\%), the handgrip strength of group III reduced by $14.24 \%$ and $11.07 \%$ for dominant and opposite hand respectively. The data shows that grip strength is reduced for both hands with the increasing age. The t-test is conducted and its statistics reveal that grip strength for younger group i.e. I (20-29 years) and group II is significantly higher than the grip strength of group III for both the hands $(\mathrm{p}<0.05)$. Handgrip strength for various age groups is shown with the help of (Figure 2). BMI for the group I is found to be significantly different from group II and the whole sample. The average BMI of group II and whole sample are also found significantly different $(\mathrm{p}<0.05)$.

\subsection{Comparison of the handgrip strength of present study with the other regions of India}

The t-test is performed to compare the mean handgrip strength of present study (Haryana state) with the population of other states of India viz., Madhya Pradesh (MP), Jammu and Kashmir (J \& K), Orissa (OR), Maharashtra (MH) and Tamil Nadu (TN). The results indicate that the handgrip strength of Haryana population is significantly different $(\mathrm{p}<0.05)$ from all other states for both hands (Table 4).

\section{DISCUSSION}

It is well accepted that usually musculoskeletal disorders are caused due to mismatch between anthropometric characteristics of user \& equipment. In this study, isometric handgrip strength data is provided (Haryana male agricultural workers), which is very useful to design and modify the manual tools. As from Table 4, it is clear that there is high spread among the grip strength of agricultural population of India. Author has recommended the careful selection of critical parameters for the design of equipment if there is greater variability in biomechanical strength among individuals [19]. Observed significant variations in anthropometric characteristics of farmers in present study may be due to the reasons observed by author that muscular strength of the population varies due to different geographical locations and genetic behaviour [20]. In the present research, it is observed that isometric handgrip strength is indirectly proportional to age (increase in age causes declination in grip strength significantly). Comparison of handgrip strength of north Indian male farmers with the farmers of other states of India viz., J \& K, MP, MH, OR and TN for the both hands (Dominant hand and Opposite hand) shows that north Indian farmers are strongest followed by Tamil-Nadu and Orissa farmers respectively. Therefore, results of present study indicate that knowledge and understanding of body characteristics (human capabilities, strength and limitations) of region-specific population is very important for the safe and better design agricultural tools and equipment.

\section{GRIP STRENGTH IMPLICATIONS IN DESIGN OF EQUIPMENT}

Generally dominating handgrip strength is observed higher than that of opposite hand [21, 22]. For the suitable design/modification of manual agricultural tools, force exertion for repetitive task should not cross the limit (30\% of the $5^{\text {th }}$ percentile) of strength capabilities of workers. However, it may go up to $50 \%$ for the activities, which are not prolonged more than five minutes $[18,23,24]$. It has been observed that grip strength declines significantly as age increases. However, it is well known that for a safer design of product or equipment, it must be safe for its weakest element. Hence Agricultural tool must be designed according to $5^{\text {th }}$ percentile of the weakest age group. The mean grip strength for the age group of greater than 40 years is $40.75 \pm 5.92 \mathrm{~kg}$ and $40.29 \pm 7.73 \mathrm{~kg}$ for dominant hand and opposite hand respectively. Therefore, $5^{\text {th }}$ percentile is $30.18 \mathrm{~kg}$ and $26.14 \mathrm{~kg}$ for dominant and opposite hand respectively. For repetitive type of activities $30 \%$ of the $5^{\text {th }}$ percentile must be consider for the design and it is calculated as $9 \mathrm{~kg}$ and $7.8 \mathrm{~kg}$ for dominant and opposite hand respectively. Hence the safer equipment design for a larger population must be designed considering the lesser grip strength, which is 7.8 $\mathrm{kg}$.

\section{CONCLUSION}

In the present research, Isometric handgrip strength of 200 male agricultural workers from Haryana state is measured for both hands (dominant and opposite hand). The results are compared with the handgrip strength of the agricultural population of other states of India and it is observed that mean handgrip strength of Haryana farmers differs significantly $(p<0.05)$ than those of other regions of India. These results and significant difference in strength capabilities of Haryana population suggests that the manual agricultural tools designed for the population from other regions are not ergonomically right for Haryana population. Therefore, the strength data of Haryana agricultural workers presented in this paper is important for the design of manual agricultural tools and equipment for aforesaid population. For future scope, authors propose the data collection for Haryana population for a larger sample from all districts to establish the better database for future references. 


\section{REFERENCES}

[1] Kumar, A., Mohan, D., Mahajan, P. (1998). Studies on tractor related injuries in northern India. Accident Analysis \& Prevention, 30(1): 53-60. https://doi.org/10.1016/S0001-4575(97)00061-4

[2] Woodson, W.E., Conover, D.W. (1973). Human Engineering Guide for Equipment Designers. 2nd Edition, University of California Press.

[3] Mital, A., Kilbom, A., Kumar, S. (2000). Ergonomics Guidelines and Problem Solving. Elsevier Ergonomics, Book Series Vol. I.

[4] Mehta, C.R., Tiwari, P.S., Rokade, S., Pandey, M.M., Pharade, S.C., Gite, L.P., Yadav, S.B. (2007). Leg strength of Indian operators in the operation of tractor pedals. International Journal of Industrial Ergonomics, 37(4):

283-289.

https://doi.org/10.1016/j.ergon.2006.10.025

[5] Yadav, R., Sahastrarashmi, P., Patel, N.C., Gite, L.P. (2010). Analytical study of strength parameters of Indian farm workers and its implication in equipment design. Agricultural Engineering International: The CIGR eJournal, 12(2): 49-54.

[6] Patel, T., Karmakar, S., Sanjog, J., Kumar, S., Chowdhury, A. (2013). Socio-economic and environmental changes with transition from shifting to settled cultivation in North-Eastern India: an ergonomics perspective. International Journal of Agricultural Science and Research, 3 (2): 117-136.

[7] Patel, T., Sanjog, J., Kumar, P., Karmakar, S. (2014). Isometric muscular strength data of Indian agricultural workers for equipment design: Critical analysis. Agricultural Engineering International: CIGR Journal, 16(2): 70-79.

[8] Sartorio, A., Lafortuna, C.L., Pogliaghi, S., Trecate, L. (2002). The impact of gender, body dimension and body composition on hand-grip strength in healthy children. Journal of Endocrinological Investigation, 25(5): 431435. https://doi.org/10.1007/BF03344033

[9] Visnapuu, M., Jurimae, T. (2007). Handgrip strength and hand dimensions in young handball and basketball players. The Journal of Strength \& Conditioning Research, 21(3): 923-929. https://doi.org/10.1519/15334287(2007)21[923:HSAHDI]2.0.CO;2

[10] Wu, S.W., Wu, S.F., Liang, H.W., Wu, Z.T., Huang, S. (2009). Measuring factors affecting grip strength in a Taiwan Chinese population and a comparison with consolidated norms. Applied Ergonomics, 40(4): 811815. https://doi.org/10.1016/j.apergo.2008.08.006

[11] Imrhan, S.N. (1999). In Hand grasping, finger pinching, and squeezing. Kumar, S., (Ed.), Biomechanics in Ergonomics, Taylor and Francis, London, 97-109. https://doi.org/10.1201/9780849379093.ch9
[12] Burke, W.E., Tuttle, W.W., Thompson, C.W., Janney, C.D., Weber, R.J. (1953). The relation of grip strength and grip-strength endurance to age. Journal of Applied Physiology, 5(10): 628-630. https://doi.org/10.1152/jappl.1953.5.10.628

[13] Carmelli, D., Reed, T. (2000). Stability and change in genetic and environmental influences on hand-grip strength in older male twins. Journal of Applied Physiology, $89(5)$ : 1879-1883, https://doi.org/10.1152/jappl.2000.89.5.1879

[14] Dewangan, K.N., Gogoi, G., Owary, C., Gorate, D.U. (2010). Isometric muscle strength of male agricultural workers of India and the design of tractor controls. International Journal of Industrial Ergonomics, 40(5): 484-491. https://doi.org/10.1016/j.ergon.2010.05.008

[15] Patel, T., Sanjog, J., Karmakar, S. (2015). Isometric handgrip strength of agricultural workers from northeast region of India. AgricEngInt: CIGR Journal, 17(1): 130140.

[16] Newman, D.G., Pearn, J., Barnes, A., Young, C.M., Kehoe, M., Newman, J. (1984). Norms for hand grip strength. Archives of Disease in Childhood, 59(5): 453459. http://dx.doi.org/10.1136/adc.59.5.453

[17] Kumar, S. (1991). Arm lift strength in workspace. Applied $\quad$ Ergonomics, 22(5): 317-328. https://doi.org/10.1016/0003-6870(91)90388-X

[18] Gite, L.P., Majumder, J., Mehta, C.R., Khadatkar, A. (2009). Anthropometric and Strength Data of Indian Agricultural Workers for Farm Equipment Design. CIAE, Bhopal, India.

[19] Roebuck, J.A., Kroemer, K.H.E., Thomson, W.G. (1975). Engineering Anthropometry Methods. John Wiley and Sons, New York.

[20] Gite, L.P., Singh, G. (1997). Ergonomics in agriculture and allied activities in India. Technical Bulletin No. CIAE/97/70, Bhopal, India.

[21] Bechtol, C.O. (1954). Grip test the use of a dynamometer with adjustable handle spacings. The Journal of Bone \& Joint Surgery, 36(4): 820-832.

[22] Petersen, P., Petrick, M., Connor, H., Conklin, D. (1989). Grip strength and hand dominance: Challenging the $10 \%$ rule. American Journal of Occupational Therapy, 43(7): 444-447. https://doi.org/10.5014/ajot.43.7.444

[23] Agrawal, K.N., Singh, R.K.P., Satapathy, K.K. (2009). Isometric strength of agricultural workers of Meghalaya: A case study of an Indian population. International Journal of Industrial Ergonomics, 39(6): 919-923. https://doi.org/10.1016/j.ergon.2009.06.008

[24] Tiwari, P.S., Gite, L.P., Majumder, J., Pharade, S.C., Singh, V.V. (2010). Push/pull strength of agricultural workers in central India. International Journal of Industrial $\quad$ Ergonomics, $40(1)$ : 1-7. https://doi.org/10.1016/j.ergon.2009.10.001 